Draft, 27 April 2021. The Oxford Handbook of Cultural Evolution, edited by Rachel Kendal, Jamie Tehrani \& Jeremy Kendal

\title{
HENRICH, HEYES, AND TOMASELLO ON THE COGNITIVE FOUNDATIONS OF CULTURAL EVOLUTION
}

\author{
Cecilia Heyes \\ All Souls College \& Department of Experimental Psychology \\ University of Oxford, Oxford OX1 4AL \\ cecilia.heyes@all-souls.ox.ac.uk \\ http://users.ox.ac.uk/ ascch/
}

\&

Richard Moore

Department of Philosophy

University of Warwick, Coventry CV4 7AL

richard.moore@warwick.ac.uk

https://warwick.ac.uk/fac/soc/philosophy/people/summaries/moore/

Words -4981 


\section{Henrich, Heyes and Tomasello on the Cognitive Foundations of Cultural Evolution}

Abstract

We give a brief overview of three accounts of the cognitive abilities that facilitated the emergence and transmission of cumulative culture in the recent hominin lineage. These accounts were developed by Joseph Henrich (e.g. 2016), Cecilia Heyes (e.g. 2018), and Michael Tomasello (e.g. 1999, 2008, 2014) in collaboration with others. We pay particular attention to the different abilities that these authors think are foundational to human cultural evolution, and to questions about whether these abilities first arose as products of genetic or cultural evolution. Our hope is that by clarifying the similarities and differences between these projects, we will identify points of disagreement that could tested empirically, and areas where further conceptual clarification is required.

Keywords: cultural evolution, human cognition, adaptations, learning, Henrich, Heyes, Tomasello

\section{Introduction}

One way to make sense of the explanatory potential of cultural evolution, and particularly its role in the historical emergence of uniquely human forms of cognition, is to compare the cognitive traits that are taken to be precursors of human cultural evolution with those that are taken to be products. Since contemporary contributors sometimes disagree about which states are precursors to and which are products of cultural evolution, a systematic (if short) overview of some differences may be useful. Not least, it could help us to clarify where differences exist, and the extent to which they are points of genuine disagreement or mere differences of emphasis. By clarifying key differences between existing views, we hope to provide a foundation for evaluating these differences.

A number of traits are taken to be central to cultural evolution: 'innovation', 'social learning', 'teaching' and 'social learning biases' (e.g. 'conformity', 'prestige') are all understood to underwrite the inheritance system that distinguishes cultural from genetic evolution. Together they explain both how practices and technologies persist over generations, and why they also increase in complexity (Legare \& Nielsen 2015). However, 
most cultural evolutionists use the "phenotypic gambit" (Grafen 1984); they investigate the effects of these traits on behaviour while remaining agnostic about how the traits work and where they come from (Heyes 2016a; Hoppitt \& Laland 2013). They do not ask what is going on in agents' minds when they innovate, learn or teach, or about the evolutionary and developmental origins of these cognitive operations. This chapter focusses on three notable exceptions: Joseph Henrich, Cecilia Heyes, and Michael Tomasello who, working with many collaborators, have all defended accounts of the cultural and cognitive foundations of the human mind. Heyes and Tomasello have additionally investigated how the cognitive processes in question work - what goes on in agents' minds - and the evolutionary origins of these processes. They are not the only cultural evolutionists interested in minds, but in comparing and contrasting their research programmes we aim to identify key areas of disagreement in research on the cognitive foundations of culture, and thereby to lay the ground for synthetic theoretical and empirical work.

In section one we give some background on each of the three research programmes. In section two, we consider how each programme conceptualises cognition, genetic evolution, culture and cultural evolution. We then survey what each programme takes to be the most important cognitive processes contributing to culture (section three), and what they claim about the origins of cultural cognition (section four).

\section{Roots}

Henrich's background lies at the intersection of cultural evolutionary anthropology and computational modelling. The theoretical foundation of his research programme is rooted in the dual-inheritance theory of Boyd and Richerson (1976) and Cavalli-Sforza and Feldman (1981), a theory that sees human behaviour as a product of two interacting inheritance systems, genetic and cultural evolution. In his "highly interdisciplinary version of evolutionary psychology" (Henrich \& Muthukrishna 2021), cross cultural research on behavioural economics is combined with the sociobiological and psychological ingredients of classical evolutionary psychology (Barkow, Cosmides \& Tooby 1992; Pinker 1994).

Typically, empirical studies by Henrich and collaborators examine non-"WEIRD" human societies - that is, societies that are not western, educated, industrialised, rich and democratic (Henrich, Heine \& Norenzayan 2010; Henrich 2020), often with experiments in which the cooperative behaviour of people from WEIRD and non-WEIRD societies is 
compared using economic games. These studies show substantial behavioural response variation across cultures - for example, in how different groups of people distribute rewards in accordance with fairness norms. These between-group differences are used to argue for two claims about the centrality of culture in human history and phylogeny. First, after Richerson and Boyd, Henrich argues that many of the behaviours that have allowed humans to survive in local ecologies are derived from local cultural practices passed down (often blindly) across generations, and not from genetic changes. These strategies are often specialised to support survival in local conditions, and they fulfil functions that might once have been assumed to be the product of biological adaptations. Second, these cultural innovations have given rise to further genetic changes, such that human behaviour is now a product of gene-culture co-evolution.

Thus, Henrich takes humans to be more diverse than might be supposed by proponents of classical evolutionary psychology. These differences are the products of cultural adaptations to local environments, and of gene-culture co-evolution.

Heyes drank from one of the same wells as Boyd and Richerson (1985); like them, she was influenced by Donald Campbell's work on cultural evolution $(1965,1974)$. But her disciplinary roots are in cognitive science - psychology and philosophy - rather than anthropology and economics. Her evidence, produced and sifted, comes from comparative and developmental psychology, experimental psychology, and cognitive neuroscience; from adults, children and a range of nonhuman animals. Without embracing 'memes', she draws on Dennett (2001) and other philosophers of biology (Godfrey-Smith 2012, Shea 2013, Sterelny 2012). Heyes is a critic of evolutionary psychology. She admires the founders' vision, to integrate cognitive psychology with evolutionary theory, but rejects the nativism of classical evolutionary psychology. Heyes's experimental work provides evidence that imitation and mirror neurons, assumed by many to be genetic adaptations, are products of associative learning in a rich sociocultural environment. In her commentaries on published experimental work with human and nonhuman primates, Heyes argues that hypotheses have not been tested rigorously, and that 'leaner' explanations - appealing to domaingeneral psychological processes found in a wide range of animals - can account for the same data. Her longer papers and recent book (Heyes 2018, 2019a) are less deflationary. She has formulated a positive view suggesting that many human cognitive abilities are themselves products of cultural evolution. These culturally evolved skills build on a modest initial 
'starter kit' of genetically inherited cognitive traits, qualitatively similar to those of other primates.

Tomasello is a developmental psychologist influenced by the constructivism of Piaget, Vygotsky and philosophers of mind, language, and psychology including John Searle, Paul Grice, and Michal Bratman. An incisive and influential critic of the idea that language is an 'instinct' made possible by an innate Chomskyan Universal Grammar (Tomasello 2003), his early work developed the constructivist idea that much of human reality is a product of our social interactions. Not only was the grammar of our language grounded in these interactions, much of what makes human life distinct was too. This included the "institutional reality" (Searle 1995, 2010; Rakoczy \& Tomasello 2007; Tomasello 2014, 2015) of social norms and socially conferred roles - things the nature of which is determined by human practices, rather than natural kinds. His views on cognition, culture and cultural evolution are informed primarily by the extensive empirical work of his own research group, in which children and a range of captive nonhuman apes are given bespoke tests of social cognitive functioning. By identifying differences in what can be achieved by young children and great apes, Tomasello has sought to identify the components of the starting set that make children different from great apes, and that enable the development of our institutional reality. Young children have been a particular focus of Tomasello's work because he recognises that, with the development of natural language (from around 15 months) and ever greater immersion in cultural practices, children's cognition changes. Since apes are taken/shown to be less submerged in culture than are humans, comparisons of pre-school children and non-human great apes provide us with valuable insights into the ways in which their 'start-up kits' (Frith 2001) differ.

Henrich, Heyes and Tomasello have roughly the same overarching purpose: to explain from an evolutionary perspective why human lives are so different from those of other animals - "the secret of our success" (Henrich 2015). They all believe that our capacity to learn from one another is a key part of the "secret". However, Henrich and Tomasello are more preoccupied than Heyes with the evolution of large-scale cooperation or "ultrasociality" (Campbell 1993) - cooperation and exchange among anonymous strangers and Tomasello and Heyes are more intent than Henrich on explaining the nature and ontogenetic development of human cognition. They also have different approaches to theory evaluation. Heyes typically adopts a comparative approach, in which she pits 
alternative hypotheses or models against one another, asking which provides a better fit with the data. In contrast, Henrich and Tomasello typically use a more single-minded approach, in which they advance new hypotheses on the strength of their consistency with data produced (primarily) in their own labs. On this approach, evaluating existing hypotheses takes a back seat to the exploration of ambitious new ones.

\section{Conceptual apparatus}

Henrich, Heyes and Tomasello are all 'cognition liberals', using the term for all sorts of adaptive processing of knowledge or information, rather than 'cognition conservatives', who reserve it for especially complex or impressive forms of information processing (Allen 2017; Bayne et al. 2019). Heyes is firmer than Henrich or Tomasello in distinguishing cognition from motivation (e.g. beliefs from preferences), but from time-to-time they all use 'cognitive' as a synonym for 'psychological'. They are also alike in using 'genetic evolution' to refer to natural selection operating on genetic variants, and, although sympathetic to some aspects of the Extended Evolutionary Synthesis (Laland et al. 2015), they share a Modern Synthesis conception of how genetic evolution operates.

Differences emerge in the trio's uses of 'culture', 'cultural learning' and 'cultural evolution'. Henrich follows Boyd and Richerson (1985) in defining culture broadly as information and behaviour acquired through social learning, and therefore embraces the idea that, although humans are especially reliant on culture, culture is present in a wide range of species. In contrast, Heyes and Tomasello use 'culture' to refer to what is also known as 'cumulative culture' - that is, to socially learned characteristics (e.g. information, behaviour, artifacts) that have undergone directional change or improvement over time, or which have the potential to do so (Heyes 2020; Mesoudi \& Thornton 2018). Accordingly, Henrich uses 'cultural learning' to refer to all human social learning (Henrich 2015), whereas Heyes and Tomasello (who coined the term) reserve 'cultural learning' for social learning that has been specialised for cumulative culture (Heyes 2018; Tomasello, Kruger \& Ratner 1993).

Tomasello also uses 'cultural evolution' to refer to cumulative culture, improvement or 'ratcheting' of socially learned characteristics (Tennie, Call \& Tomasello 2009), while Henrich is more liberal. He uses 'cultural evolution' to refer, not only to 1) cumulative culture, but also 2) change in socially learned characteristics where there is no apparent 
direction or improvement, and 3) change in socially learned characteristics that is due to a Darwinian process based on variation and selective retention (Campbell 1974). The second of these options is more inclusive, and the third is less inclusive, than the first (Figure 1). Heyes describes (1) and (3), but not (2), as cultural evolution, and usually tags (3) as 'cultural selection'. Tomasello has neither contested nor endorsed the idea that cumulative culture can occur via a Darwinian process.

Figure 1. Uses of 'cultural evolution'. See text for details.

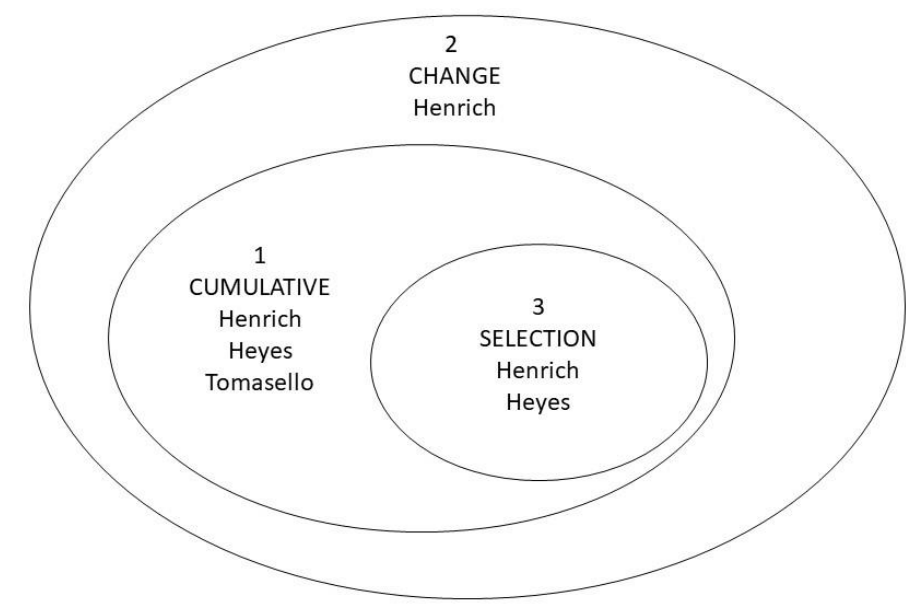

\section{Cognitive processes}

At first glance, Henrich, Heyes and Tomasello seem to disagree profoundly about the cognitive foundations of culture. For example, Henrich emphasises 'selective social learning' and 'norm psychology'; Heyes discusses selective social learning but foregrounds 'imitation' and 'metacognition'; and Tomasello is preoccupied with 'joint attention' and 'shared intentionality' - although in more recent work, the understanding of social norms has also come to play a prominent role. Nonetheless this variation does not necessarily indicate disagreement. Due to their contrasting disciplinary roots, the three use different cognitive ontologies (Janssen, Klein \& Slors 2017); they categorise cognitive processes in different ways. For example, Heyes's use of 'metacognition' comes from experimental psychology and cognitive neuroscience where, drawing on the computer metaphor that dominates those disciplines, it refers to assessment by a cognitive system of that system's 
own states and processes. In contrast, 'norm psychology' is a term coined by Henrich and his collaborators to refer to processes "for noticing and responding to social norms" (Chudek 2018). It is a new category but the categorisation strategy comes from classical evolutionary psychology, where it is common to distinguish types of psychological processes according to the role they are thought to play in enhancing reproductive fitness. Similarly, 'shared intentionality' is a term coined by Tomasello to refer to the cognitive and motivational states that permit subjects to engage in collaborative activities, including joint attention and, ultimately, institutional reality. The term is new but draws elements from the philosophical literature on joint action developed mostly by Searle (1995, 2010), Bratman (1999), and Gilbert (1989), without sticking too closely to any of these accounts.

Because they use different cognitive ontologies, it is no simple matter to work out where Henrich, Heyes and Tomasello agree and disagree about the cognitive foundations of culture, or, in cases of disagreement what would count as evidence in favour of one view over another. In a first attempt to tackle this problem, we will outline briefly what each of the three has claimed and point out what appear to be convergent and divergent themes (see Figure 2).

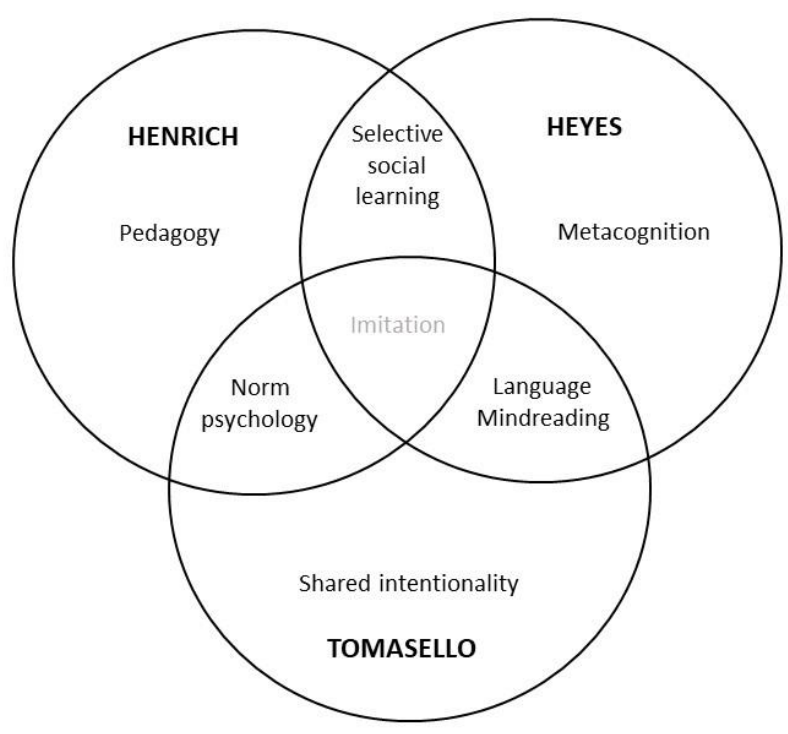

Figure 2. Cognitive processes contributing to human cultural evolution 
Henrich - selective social learning and norm psychology

The work of Henrich and his colleagues suggests that 'cultural learning psychology' and 'norm psychology' are important for cultural evolution (Chudek \& Henrich 2010). 'Cultural learning psychology' is a portmanteau containing 'high fidelity social learning', 'overimitation', 'pedagogy', 'larger brains' and 'selective social learning'. These are combined into a single category because they are all assumed to increase the probability that cultural inheritance will be cumulative by helping people to acquire, organise and store information from other agents, but only selective social learning is discussed in any depth. Social learning is said to be 'selective', or 'biased', when some kinds of content are more likely than others to be learned (Barrett \& Broesch 2012, Sperber 1996), or when the influence of a model's behaviour on an observer's behaviour varies with the circumstances of the encounter or with features of the model. For example, there is evidence from adults and children in a range of cultures that model observation has a greater impact when the environment has recently changed (known as a copy when uncertain social learning strategy; Laland 2004; Rendell et al 2011), and when the model is older than the observer, similar to the observer in sex and ethnicity, or is skilled, successful, and prestigious (reviewed in Chudek, Brosseau-Liard, Birch \& Henrich 2013). Henrich is agnostic about the 'proximate explanation' of selective social learning - for example, about the psychological processes that make observers favour one model over another - but firm in believing that selective social learning enhances reproductive fitness in populations where there is a high volume of socially learned behaviour.

Norm psychology consists of two collections of "cognitive mechanisms, motivations and dispositions" that enable people to deal with norms - that is, "learned behavioural standards shared and enforced by a community" (Chudek \& Henrich 2011). The collections are distinguished by their adaptive functions, not in relation to the types of psychological process (e.g. cognitive, motivational, emotional) involved. One collection detects regularities - it helps with the recognition, representation, recall and adoption of norms and the other relates to violations - it enables people to detect, condemn and punish norm violations by others; to avoid violating norms themselves (via shame); to make reparations for their own violations (via guilt); and to internalise and champion norms (via pride). 
Norm psychology, especially the part relating to violations, plays a pivotal role in Henrich's account of the origins of large-scale cooperation. He and his collaborators argue that cumulative cultural evolution among early humans, fuelled by prestige and conformity social learning biases, made the members of any given social group more like one another, and more unlike the members of other social groups. This meant that members of the same social group had much to gain from coordinating their behaviour, and coordination was facilitated by norm psychology; processes that encourage group members to punish, signal virtue, and make costly commitments under the same circumstances. Crucially, norm psychology also enabled cultural group selection of cooperative practices. Groups with one set of norms, $x$, proliferated at the expense of groups with alternative sets, $y$ and $z$. For example, groups with $x$ were more likely to win wars, compete successfully for natural resources, and attract migrants than groups with y or z. In some cases, the more successful norms were more 'prosocial'; more inclined to promote cooperation among strangers.

\section{Heyes - imitation and metacognition}

Heyes has discussed four sets of cognitive processes in detail, responsible for selective social learning, metacognition, imitation, and mindreading (or 'theory of mind') (Heyes 2018; Heyes et al. 2020). Like Henrich, she sees selectivity as enhancing the efficiency of social learning - promoting the acquisition of useful or adaptive information - in a way that helps to make culture cumulative. Unlike Henrich, she distinguishes attentional from 'explicit' or 'metacognitive' social learning biases - selectivity based, not on what grabs learners' attention, but on assessment by the learner of the reliability of their own cognition and the cognition of other agents (Heyes 2016b). She argues that, among extant animals, metacognitive biases are found only in humans (Heyes \& Pearce 2014), and that their emergence in the hominin line made it possible for knowledge and skills to undergo rapid cultural selection; to be inherited from agents other than biological parents, and to improve over cultural generations via a Darwinian process (Birch and Heyes 2020).

What Heyes (and Tomasello) call 'imitation' may be what Henrich calls 'high fidelity social learning' and 'overimitation'. Heyes defines imitation as copying the topography of body movement; for example, the way that parts of the body move relative to one another in a dance movement such as shimmying or a communicative gesture such as the 'ok' sign. Imitation has been implicated in the cumulative cultural evolution of tools, tool-making and 
tool-use (e.g. Tomasello 1999; Tennie, Call \& Tomasello 2009; Whiten et al. 2009), but Heyes suggests that it is important primarily or exclusively for the cultural evolution of ritualistic and communicative behaviour (Heyes 1993; 2013, 2020; see also Tennie, Call \& Tomasello 2012; Moore 2013). Imitation allows these behaviours to be inherited with enough fidelity for their cultural selection, and the within-group cooperation promoted by ritualistic and communicative behaviour in turn facilitates cultural selection of technology.

Many cultural evolutionists, including Henrich and Tomasello, believe that teaching or 'pedagogy', promotes high fidelity cultural inheritance and thereby cumulative culture and cultural selection (1 and 3 in Figure 1; see Moore 2016 for discussion). Heyes does not deny this, but she focusses on mindreading, the cognitive skill that she argues is the 'active ingredient' of human teaching; the component that enables experts to communicate their skills effectively to novices (Sterelny 2012; although see Moore 2016 for the view that teaching can be cognitively undemanding). She defines mindreading as cognition that enables prediction, explanation and regulation of the behaviour of others. In contemporary Western societies mindreading involves the ascription of mental states such as beliefs and desires, and promotes effective teaching by allowing an expert to model at each stage of skill development what a novice does and does not know. Like Tomasello (Lohmann \& Tomasello 2003; O’Madagain \& Tomasello 2018), Heyes sees the development of mindreading (and metacognition) as dependent on conversation - language-based social interaction.

Compared with Henrich and Tomasello, Heyes has said very little about the cognitive processes involved in generating and responding to norms. She has only endorsed the view that they depend on domain-general Bayesian inference and reinforcement learning, and identified ways of finding out whether this 'moral learning' is primed by genetically inherited prosocial biases (Heyes 2019b).

\section{Tomasello - from shared to collective intentionality}

A consistent feature of Tomasello's work has been his focus on identifying the cognitive abilities that are present in young children and absent in great apes, and which might therefore be recruited to explain the development of human thought and society. In Tomasello's earlier work these skills included joint attention, 'cooperative communication', and imitation - which Tomasello thinks were all necessary for the development of language 
$(1999,2008)$. Together cooperation and language subsequently enabled the development of human forms of cognition and culture $(1999,2008)$, including social institutions, and objective ways of thinking about the world and our place in it $(2014,2015)$. These abilities all fall under the rubric of what in more recent years he has called 'skills and motivations for shared intentionality' (Tomasello 2020). In Tomasello's work (2008), 'cooperative communication' incorporates two ideas found in Grice (1989) - namely, the production and comprehension of communicative intentions, and the cooperative foundations of communication (Moore 2018) - and applies these to the development of uniquely human forms of communication (Tomasello 2008; Herrmann \& Tomasello 2006; Moore). Together these skills and motivations for shared intentionality constitute a set of adaptations that, Tomasello argues, arose to support human life in small-scale social groups, under selection pressure for obligate collaborative foraging (Tomasello et al. 2012; Tomasello 2014, 2019). This round of adaptations was the first of what Tomasello has called 'two key steps' in human evolution. In a second round, humans acquired a suite of adaptations for norm cognition, under selection pressure for new abilities to facilitate living harmoniously in larger scale communities. These later developing adaptations gave rise to a new set of cognitive abilities for 'collective intentionality', which enabled normative thinking. Tomasello takes this to be foundational to the existence of human social institutions (2014), morality (2015), and even some objective forms of thought (2014). Whereas some abilities for shared intentionality are in place around children's first birthday, abilities for collective intentionality start to mature only when children are around three years of age.

In summary (see Figure 2): Tomasello and Henrich both emphasise the importance of norm psychology for the emergence of uniquely human cognition; Henrich and Heyes share an interest in selective social learning; and Heyes and Tomasello both believe that language is needed for the development of some forms of cultural cognition, such as mindreading. All three authors discuss imitation, but both Heyes and Tomasello have argued that imitation plays a more limited and specific role in cultural evolution than previously assumed (Heyes, 1993; Heyes, under review; Tomasello 2009). Pedagogy is highlighted only by Henrich, metacognition only by Heyes, and shared intentionality only by Tomasello, but this divergence may not indicate disagreement. They all assume that pedagogy, understood as teaching of some sort, contributes to human cultural evolution; shared intentionality is a 
generic term for processes that Henrich and Heyes have no reason to deny are important; and 'metacognition' might be one of those processes.

Conceptual work is needed to synthesise the contributions of Henrich, Heyes and Tomasello into a clearer set of hypotheses about cultural cognition. We need greater clarity on how each author is using terms of art, and what they take to be the role of each cognitive process in enabling cultural evolution. For example, what exactly is going on in an agent's mind when they share intentionality? Is it sometimes / always / never a form of mindreading? And what is the relationship between mindreading and metacognition? At the mind level, how does detecting a behavioural norm differ from detecting a common pattern of asocial behaviour, perhaps in prey species? Do psychologically distinct kinds of selective social learning (e.g. attentional and metacognitive) make the same or different contributions to cultural evolution? Answers to this kind of question are needed, so that we can identify plausible pairs of alternative hypotheses and test them empirically.

\section{Evolutionary processes}

Turning from cognitive to evolutionary processes, the contrasts between Henrich, Heyes and Tomasello become clearer and therefore more interesting. They all assume that genetic evolution, natural selection operating on genetically inherited variants, and cultural inheritance have contributed interactively to the emergence of cognitive processes specialised for cultural evolution. In this sense, they could all be described as gene-culture (or culture-gene) co-evolutionists with respect to cultural cognition. However, the roles they assign to genes and culture are very different.

Henrich argues that culturally inherited information - embodied in tools, techniques, and norms - has been a powerful source of selection pressure for the genetic evolution of cultural cognition: "By generating increasingly complex tools (e.g. spearthrowers), food processing techniques (e.g., cooking), languages (e.g., larger vocabularies) and institutions (e.g., clans) over hundreds of thousands of years, cumulative cultural evolution has shaped the environments faced by our genes and thereby drove the genetic evolution of the uniquely human aspects of our bodies and minds" (Henrich \& Muthukrishna, 2021, p. 20). This view implies that, in contemporary humans, whereas the 'grist' of culture - tools, techniques, norms - are culturally inherited, the cognitive processes that enable the inheritance of grist, the 'mills' - 'cultural learning psychology' and 'norm psychology' - are 
genetically inherited. Each child is born with a specific genetic propensity to develop these forms of cultural cognition. Of course, they need experience of various sorts for that genetic potential to be fulfilled, but, according to Henrich, selective social learning, pedagogy, norm detection and other components of the specialised cultural cognition toolkit are canalised - they would develop in broad range of environments.

Tomasello assigns more substantial and specific roles to social interaction in the childhood development of cultural cognition, but, like Henrich, he casts genetic evolution as a leading architect of the mills. Social engagements made possible by joint attention and other forms of shared intentionality build capacity for language, mindreading, and norm psychology; and extend the cognition of which humans are capable (Tomasello 2014; O'Madagain \& Tomasello 2018). Nonetheless, shared intentionality itself is a set of uniquely human genetic adaptations (Tomasello, 2020). It is not always apparent that this is Tomasello's view because he argues that the components of shared intentionality are "ontogenetic adaptations" (Tomasello, 2020). This term could mean that shared intentionality is constructed during development using non-specific genetically inherited resources - for example, resources that evolved in our prehuman ancestors under pressure from asocial environments. However, Tomasello uses "ontogenetic adaptation" in a different way - to refer to genetic adaptations that serve a purpose in juvenile life - for example, that help infants to solicit care from adults.

There are a number of claims about cognitive development on which Heyes and Tomasello agree; their views have converged in recent years. Both have argued against the Chomskyan tradition in linguistics (Tomasello 2003; Heyes 2018, 2019a); and both hold that language development enables new forms of thinking and reasoning (e.g. Lohmann \& Tomasello 2003; O’Madagain \& Tomasello 2018; Heyes 2018). Despite these points of overlap, there are disagreements. Compared with Tomasello, Heyes argues that social interaction contributes more, and genetic inheritance contributes less, to the construction of cultural cognition. In her view, social interaction during development makes cultural cognition out of "old parts" - genetically inherited attentional, motivational and learning mechanisms that evolved in early vertebrates for asocial as well as social purposes. She cites evidence that some of these old parts have been "tweaked" by genetic evolution in the hominin line - for example, making humans especially attentive to faces and voices, and more socially tolerant and motivated than our pre-hominin ancestors - but denies that 
humans genetically inherit programmes for the development of mindreading, metacognition, shared intentionality, language or any other kind of distinctively cultural cognition (Heyes 2018; 2019a). At the individual level, these mills are constructed during development through social interaction, and at the population level they are made adaptive by cultural selection. Unlike Heyes, Tomasello (1999) is resistant to the idea that domaingeneral processes of learning (variously called 'associative', 'Bayesian' and 'statistical' are key to explaining infant socio-cognitive development. Consequently, he is more inclined than Heyes to posit a richer starter-kit to explain infants' entrance into language. This places Heyes closer to the (e.g. Piagetian) empiricist tradition. Tomasello's commitments are more rationalist, and therefore both he and Henrich lie closer to classical Evolutionary Psychology.

\section{Conclusion}

The research programmes of Henrich, Heyes and Tomasello are aligned in many respects. They share the view that the cultural inheritance of behaviour, beliefs and artefacts (grist) has played a key role in making human lives so different from those of other animals, and they assume that cultural cognition - the cognitive processes that enable inheritance of grist - are products of gene-culture co-evolution. Given this common ground, it is likely that their disagreements will prove to be interpretable and subject to empirical resolution. Starting down this road, we identified variation in what the three programmes take to be the cognitive precursors and cognitive products of cultural evolution. The candidate precursors are norm psychology and cultural learning psychology (Henrich), shared and collective intentionality (Tomasello), and small quantitative changes to domain-general cognitive processes (Heyes). The candidate products are norm psychology and the psychological processes that enable cultural learning, including selective social learning, language, mindreading, and metacognition (Heyes and Tomasello). A goal of future work should be to specify more precisely the commitments of the authors considered here, such that resultant predictions could be tested empirically. The value of this comparison would lie not in proving one individual right at the expense of the others, but in advancing our understanding of the cognitive foundations and consequences of cultural evolution.

\section{Acknowledgements}

Thanks to Claudio Tennie and Mike Tomasello for very helpful comments on this chapter. 


\section{References}

Allen, C. (2017). On (not) defining cognition. Synthese 194, 4233-4249.

Barkow, J. H., Cosmides, L., \& Tooby, J. (Eds.). (1992). The adapted mind: Evolutionary psychology and the generation of culture. Oxford University Press, USA.

Barrett, H.C. \& Broesch, J. (2012). Prepared social learning about dangerous animals in children. Evolutionand Human Behavior, 33, 499-508.

Bayne, T., Brainard, D., Byrne, R.W., Chittka, L., Clayton, N., Heyes, C., Mather, J., Ölveczky, B., Shadlen, M., Suddendorf, T. and Webb, B. (2019). What is cognition? Current Biology, 29(13), R608-R615.

Birch, J. \& Heyes, C. M. (in press) The cultural evolution of cultural evolution. Philosophical Transactions of the Royal Society, B

Boyd R, Richerson P. (1976). A simple dual inheritance model of the conflict between social and biological evolution. Zygon, 11, 254-262.

Boyd, R., \& Richerson, P. J. (1988). Culture and the evolutionary process. University of Chicago Press.

Bratman, M. (1999). Faces of intention: Selected essays on intention and agency, Cambridge: Cambridge University Press.

Campbell, D. T. (1965). Variation and selective retention in socio-cultural evolution. Social Change in Developing Areas, 19, 26-27.

Campbell, D. T. (1974). Evolutionary epistemology. In P. A. Schilpp (ed.), The Philosophy of Karl Popper. LaSalle, IL: Open Court, 413-463.

Cavalli-Sforza, L. L., \& Feldman, M. W. (1981). Cultural transmission and evolution: A quantitative approach. Princeton University Press.

Chudek, M. (2018). Norm psychology. The International Encyclopedia of Anthropology, 1-5.

Chudek, M., Brosseau, P., Birch, S. \& Henrich, J. (2013). Culture-gene coevolutionary theory and children's selective social learning. In The Development of Social Cognition, eds. M Banaji, $S$ Gelman. New York: Oxford

Chudek M, Henrich J. (2010). Culture-Gene Coevolution, Norm-Psychology, and the Emergence of Human Prosociality. Trends in Cognitive Sciences. 15(5):218-26

Dennett, D. C. (2001). The evolution of culture. The Monist, 84, 305-324.

Frith, U. (2001). Mind blindness and the brain in autism. Neuron, 32, 969-979.

Gilbert, M. (1989). On Social Facts. Princeton, NJ: Princeton University Press.

Godfrey-Smith, P. (2012). Darwinism and cultural change. Philosophical Transactions of the Royal Society B: Biological Sciences, 367(1599), 2160-2170. 
Grafen A. (1984). Natural selection, kin selection and group selection. In Behavioural ecology (eds JR Krebs, NB Davies), pp. 62-84. Oxford, UK: Blackwell Scientific Publications.

Grice, H. P. (1989). Studies in the way of words. Cambridge, MA: Harvard UP.

Henrich, J. (2015). The secret of our success. Princeton University Press.

Henrich, J. (2020). The weirdest people in the world: How the west became psychologically peculiar and particularly prosperous. Farrar, Straus and Giroux.

Henrich, J., Heine, S. J., \& Norenzayan, A. (2010). Most people are not WEIRD. Nature, 466(7302), 2929.

Henrich, J., \& Muthukrishna, M. (2021). The origins and psychology of human cooperation. Annual Review of Psychology, 72, 207-240.

Herrmann, E., \& Tomasello, M. (2006). Apes' and children's understanding of cooperative and competitive motives in a communicative situation. Developmental Science, 9(5), 518-529.

Heyes, C. M. (1993). Imitation, culture and cognition. Animal Behaviour, 46(5), 999-1010.

Heyes, C. M. (2013) What can imitation do for cooperation? In K. Stereiny, R. Joyce, B. Calcott, \& B Fraser (Eds.) Cooperation and Its Evolution. MIT Press.

Heyes, C. M. (2016a). Blackboxing: social learning strategies and cultural evolution. Philosophical Transactions of the Royal Society: B, 371,20150369

Heyes, C. M. (2016b). Who knows? Metacognitive social learning strategies. Trends in Cognitive Sciences, 20,204-213

Heyes, C. (2018). Cognitive gadgets: The cultural evolution of thinking. Harvard University Press.

Heyes, C. (2019a). Précis of cognitive gadgets: The cultural evolution of thinking. Behavioral and Brain Sciences, 42.

Heyes, C.M. (2019b) Is morality a gadget? Nature, nurture and culture in moral development. Synthese, https://doi.org/10.1007/s11229-019-02348-w

Heyes, C. M. (2020). Culture primer. Current Biology.

Heyes, C. M. (under review) Imitation and culture: what gives? Mind \& Language.

Heyes, C. M. \& Pearce, J. M. (2015). Not-so-social learning strategies. Proceedings of the Royal Society of London:B., 282, 20141709.

Hoppitt, W., Laland, K.N. (2013). Social learning: an introduction to mechanisms, methods, and models. Princeton, NJ: Princeton University Press.

Janssen, A., Klein, C., \& Slors, M. (2017). What is a cognitive ontology, anyway? Philosophical Explorations, 20:2, 123-128. 
Laland, K. N. (2004). Social learning strategies. Animal Learning \& Behavior, 32(1), 4-14.

Laland, K.N., Uller, T., Feldman, M.W., Sterelny, K., Müller, G.B., Moczek, A., Jablonka, E. and OdlingSmee, J. (2015). The extended evolutionary synthesis: its structure, assumptions and predictions. Proceedings of the Royal Society B: Biological Sciences, 282(1813), p.20151019.

Legare, C. H., \& Nielsen, M. (2015). Imitation and innovation: The dual engines of cultural learning. Trends in Cognitive Sciences, 19(11), 688-699.

Lohmann, H., \& Tomasello, M. (2003). The role of language in the development of false belief understanding: A training study. Child Development, 74(4), 1130-1144.

Mesoudi, A., \& Thornton, A. (2018). What is cumulative cultural evolution? Proceedings of the Royal Society B, 285(1880), 20180712.

Moore, R. (2013). Imitation and conventional communication. Biology and Philosophy, 28(3): 481-500.

Moore, R. (2016). Pedagogy and social learning in human development. For the J. Kiverstein (ed.) Routledge Handbook of Philosophy of the Social Mind. London: Routledge, pp.35-52.

Moore, R. (2017). Social cognition, Stag Hunts, and the evolution of language. Biology and Philosophy. 32(6): 797-818.

Moore, R. (2018). Gricean communication, joint action, and the evolution of cooperation. Topoi, 37(2), 329-341.

O'Madagain, C., \& Tomasello, M. (2019). Joint attention to mental content and the social origin of reasoning. Synthese.

Pinker, S. (1994). The language instinct: How the mind creates language. Penguin UK.

Rakoczy, H., \& Tomasello, M. (2007). The ontogeny of social ontology: Steps to shared intentionality and status functions. In Intentional acts and institutional facts (pp. 113-137). Springer, Dordrecht.

Richerson, P. J., \& Boyd, R. (2005). Not by genes alone: How culture transformed human evolution. University of Chicago press.

Searle, J. (1995). The construction of social reality, New York: The Free Press.

Searle, J. (2010). Making the social world: The structure of human civilization, New York: OUP.

Shea, N. (2013). Inherited representations are read in development. The British Journal for the Philosophy of Science, 64(1), 1-31.

Sperber D. (1996). Explaining culture: A naturalistic approach. Oxford, UK: Blackwell.

Sterelny, K. (2012). The Evolved Apprentice. MIT press.

Tennie, C., Call, J., \& Tomasello, M. (2009). Ratcheting up the ratchet: on the evolution of cumulative culture. Philosophical Transactions of the Royal Society B: Biological Sciences, 364(1528), 24052415. 
Tennie, C., Call, J., \& Tomasello, M. (2012). Untrained chimpanzees (Pan troglodytes schweinfurthii) fail to imitate novel actions. PLoS One, 7(8), e41548.

Tomasello, M. (1999). The cultural origins of human cognition. Cambridge, MA: Harvard UP.

Tomasello, M. (2003). Constructing a language. Cambridge, MA:Harvard University Press.

Tomasello, M. (2008). Origins of human communication. Cambridge, MA: MIT.

Tomasello, M. (2009). The question of animal culture, plus postscript (chimpanzee culture, 2009). In: K. N. Laland \& B. G. Galef (eds.), The Question of Animal Culture. Boston, MA: Harvard UP.

Tomasello, M. (2014). A natural history of human thinking. Cambridge, MA: Harvard UP.

Tomasello, M. (2015). A natural history of human morality. Cambridge, MA: Harvard UP.

Tomasello, M. (2018). How children come to understand false beliefs: A shared intentionality account. Proceedings of the National Academy of Sciences, 115(34), 8491-8498.

Tomasello, M. (2019). Becoming human: A theory of ontogeny. Belknap Press.

Tomasello, M. (2020). The adaptive origins of uniquely human sociality. Philosophical Transactions of the Royal Society B, 375(1803):20190493.

Tomasello, M., Kruger, A. C., \& Ratner, H. H. (1993). Cultural learning. Behavioral and Brain Sciences, 16(3), 495-511.

Tomasello, M., Melis, A. P., Tennie, C., Wyman, E., Herrmann (2012). Two key steps in the evolution of human cooperation: The interdependence hypothesis. Current Anthropology, 53(6), 673-692.

Whiten, A., McGuigan, N., Marshall-Pescini, S., \& Hopper, L. M. (2009). Emulation, imitation, overimitation and the scope of culture for child and chimpanzee. Philosophical Transactions of the Royal Society B: Biological Sciences, 364(1528), 2417-2428. 